Article

\title{
Experimental Analysis on Skid Damage of Roller Bearing with the Time-Varying Slip and Temperature Distribution
}

\author{
Junning Li ${ }^{1,2, *}$, Jiafan Xue ${ }^{1}$, Ka Han ${ }^{1}$, Qian Wang ${ }^{1}$ and Wuge Chen ${ }^{1}$ \\ 1 School of Mechatronic Engineering, Xi' an Technological University, Xi'an 710021, China; \\ xatujiapanxue@163.com (J.X.); xatukhan1995@outlook.com (K.H.); xatuqianw@163.com (Q.W.); \\ wgchen2018@126.com (W.C.) \\ 2 The State Key Laboratory of Mechanical Transmissions, Chongqing University, Chongqing 400044, China \\ * Correspondence: junningli@outlook.com; Tel.: +86-029-8617-3306
}

Received: 18 November 2019; Accepted: 16 December 2019; Published: 18 December 2019

\begin{abstract}
Skid damage affects the performance of aviation bearing, which covers different disciplines in tribology, thermology, materials science, dynamics, et al. In this manuscript, a novel horizontal skid damage test rig of a rolling bearing with higher rotation accuracy and better linear contact was built, which can simulate the rolling/sliding contact between the roller and inner ring. Combining with temperature, load, speed, slip, and surface microscopy, the skid damage mechanism of roller bearings was analyzed from a multi-information perspective. Meanwhile, the dynamic lubrication failure process of the contact pair in rolling bearings with the time-varying slip and temperature distribution was revealed. The effect of different radial loads, inner ring speeds, lubricating oil quantities, and states of cleanliness on the time-varying characteristics of the temperature and the slip of the rolling bearing were obtained. Among them, the radial load has the greatest influence on the slip rate of rolling bearing. In addition, the test results show that the skid damage under extremely light load is the comprehensive effect of adhesive wear and thermal failure.
\end{abstract}

Keywords: rolling bearing; skidding damage; temperature; surface microscopy

\section{Introduction}

The structure and performance of the rolling bearing, as a key part of aviation transmission, have a direct impact on the dynamics, life, and reliability of the transmission system. In the course of actual service, the failure of aviation bearing due to skidding damage has an effect on the reliability service of the main engine. Under ideal conditions, a rolling bearing should act as a planetary system with pure rolling at all surfaces. It is possible to have slip without resulting in surface damage. However, if damage does occur to the surfaces when slip is present, then this damage is more properly defined as skid damage [1]. It is necessary to point out that skidding does not necessarily cause skidding damage, but skidding damage must accompany the occurrence of the skidding phenomenon.

Bearing mechanics research has experienced four development processes: statics, quasi-statics, quasi-dynamics, and dynamics [2]. Jones [3] proposed the quasi-static analysis method and established the ring control theory of high-speed ball bearing, which could accurately obtain the load distribution, fatigue life, and stiffness of the bearing. However, the function of the lubricant is not considered, so the internal sliding of the bearing cannot be accurately predicted. Harris [4] proposed the calculation method of quasi-dynamics on the basis of quasi-statics. The equilibrium nonlinear equations of the roller, cage, and inner ring were established, which can be used to analyze the revolution, rotation speed, and bearing deformation of the roller. Then, Poplawski [5] and Rumbarger et al. [6] established a 
more comprehensive model for the quasi-dynamic analysis of roller bearing, taking into account the friction between the cage and the guide surface of the ring, and between the roller and the pocket of the cage, further refining Harris's method. With the need to analyze the dynamic performance of the rolling bearing, Walters [7] put forward the dynamic analysis model of the rolling bearing, taking into account the five degrees of freedom of the rolling body, the five degrees of freedom of the cage, the use of multiple constraint equations such as the constraint of the roller's raceway radius, and the one-dimensional integration of the contact ellipse to obtain the drag force between the roller and the inner ring. Gupta $[8,9]$ established a model for the dynamic analysis of roller bearing, which took into account the complex motion state and force state of the roller, and analyzed the velocity change of bearing parts and the influence of the corresponding inertial force. Wang et al. [10] developed a dynamic model of angular contact ball bearing and calculated the contact force and contact angles; the skidding phenomenon was investigated under the conditions of constant axial load and the combination of axial and radial load, and the relationship of contact force between the outer raceway and inner ring raceway was obtained. Khonsari et al. [11] investigated the effect of surface roughness on roller bearings operated at low speeds and under high loads, and obtained the influence of surface roughness on the film thickness and the rate of heat generation. Han et al. [12] established a nonlinear dynamic model of a cylindrical roller bearing and analyzed the variation rules of the time-varying slip rate with a time-varying load. Measures such as increasing the radial load and bending moment can prevent the bearing from skidding. Tu et al. [13] presented an analytical model to investigate skidding during rolling element bearing acceleration, and their team not only obtained the slip velocities between the roller and inner/outer race during acceleration, but also proposed the change rules of the slip ratio and speed of the roller and cage. Niu et al. [14] investigated the occurrence of cage whirl under solid lubrication conditions by using a selected dynamic model, and studied the cage whirl characteristics under stable and unstable conditions. The paper illustrated the importance of the ball-cage pocket contact force. Cao et al. [15] proposed a mathematical model to investigate skidding between the maximum loaded rollers during different acceleration speeds.

In terms of the experimental research on rolling bearing skidding behavior, Selvaraj et al. [16] developed a cylindrical roller bearing test rig, and studied the effect of the main shaft speed, radial load, viscosity of lubricating oil, number of rollers, and other working conditions on the slip rate of the roller and cage and temperature changes. As for the experimental study on the skidding damage of rolling bearing, Li et al. [17] developed a vertical contact skid damage test rig, which can simulate the actual contact status between the roller and the inner ring of the rolling bearing. In this experimental study, by changing the speed of the roller and inner ring to control the slip rate, the effects of slip rate, radial load, inner ring speed, and lubrication on skidding damage of the bearing was studied. On the basis of this test rig, Zhang et al. [18] designed an orthogonal experiment by analyzing the surface microstructure and the roller generatrix contour, and obtained the thermal effects and the main influencing factors of the rolling bearing under misalignment loads. Wu et al. [19] aimed at developing an effective online monitoring method to analyze the wear severity and wear mechanisms of bearings.

The running accuracy of the contact pair of the test rig developed by our team in the past is not high, so the load fluctuates greatly [17]. In addition, because the contact mode of the roller and inner ring is a vertical arrangement, it is difficult to ensure that the contact pair is always in line with the contact condition. At the same time, the previous test method involved studying the influence mechanism of different working conditions on the bearing skidding damage under a given slip rate, which is not suitable for a simulation of the internal relation between the actual slip rate and the skid damage under the bearing running conditions. Therefore, in this study, a horizontal skid damage test rig with a higher rotation accuracy and better line contact between the roller and inner ring was developed. The three-dimensional model of the test rig is shown in Figure 1, and the actual slip rate of the roller rotation driven by the inner ring can be measured. Based on the newly designed test rig, the purpose of this manuscript is to obtain the failure mechanism of the skidding damage of the rolling 
bearing under different inner ring speeds, radial loads, and lubrication conditions, and acquire the most critical factor leading to skidding damage.

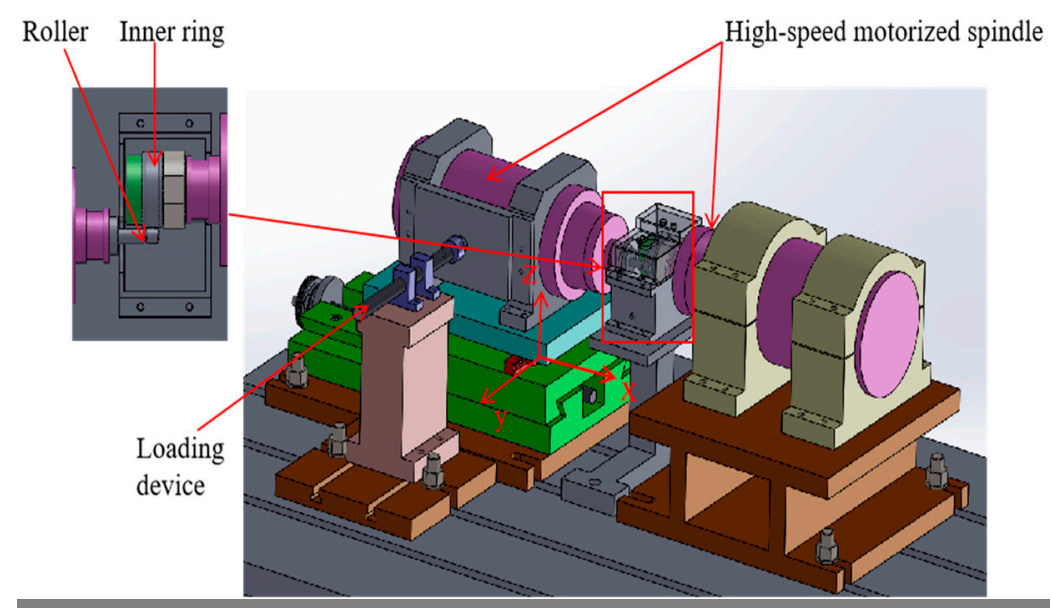

Figure 1. Three-dimensional model of the test rig.

\section{Test Rig}

\subsection{System Composition of the Test Rig}

The system composition of the test rig is shown in Figure 2, which comprises motorized spindles, a test clamping mechanism, a lubrication and cooling device, a loading device, and a test system. The overall structure of the developed test rig is shown in Figure 3, and the contact between the roller and the inner ring is in horizontal mode. In this way, the roller and inner ring attain a better linear contact.

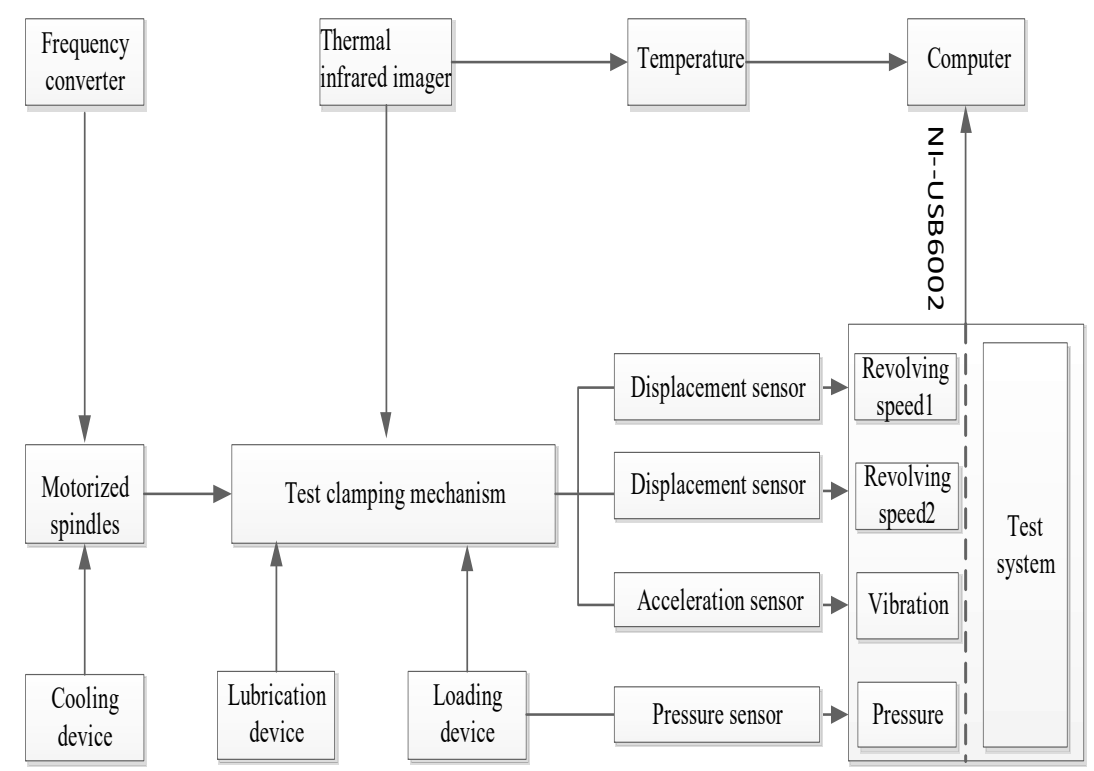

Figure 2. The system composition of the test rig. 


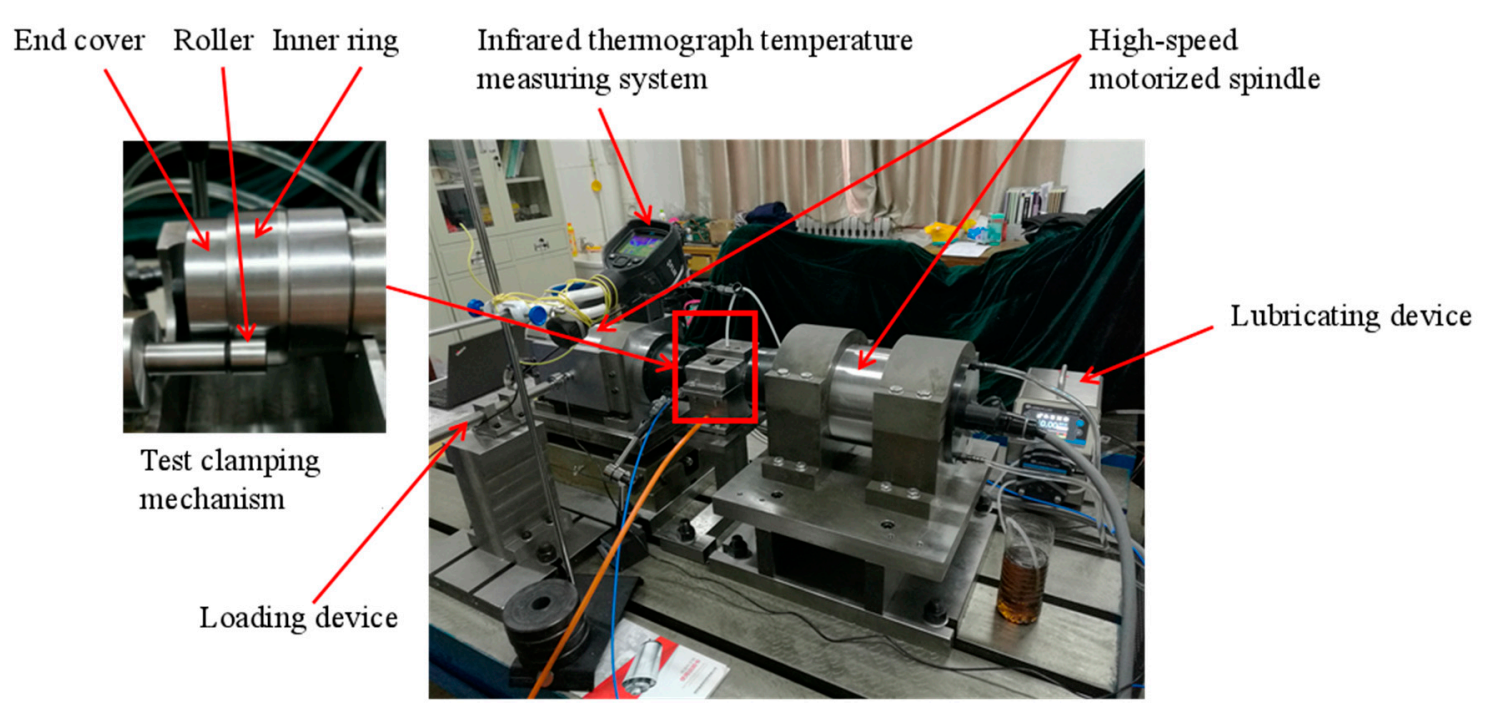

Figure 3. Overview of the skid damage test rig [20].

\subsubsection{Motorized Spindles}

The speed of the inner ring and roller is controlled by two motorized spindles, which are the core of the structural part of the test rig. In order to ensure good contact of the key contact pair, the support platform of the two motorized spindles is designed accurately, which keeps the roller and inner ring clamped at the same level. Using the dial indicator for measuring the end circular run-out error before the motorized spindles rotation, this part realized the stable running condition of the output shaft, which is attributed to the little run-out of the motorized spindles.

\subsubsection{Test Clamping Mechanism}

The test clamping mechanism is one of the most important parts of the test rig, which directly connects with the motorized spindle by the threaded connection. The roller and the fixture of the inner ring are developed. The material of the roller is $9 \mathrm{Cr} 18$, and its quenching hardness is $56 \mathrm{HRC}$. The material of the inner ring is GCr15, which was purchased from Harbin Bearing Manufacturing Co., Ltd. (Harbin, China) Figure 4 shows the testing bearing configuration.

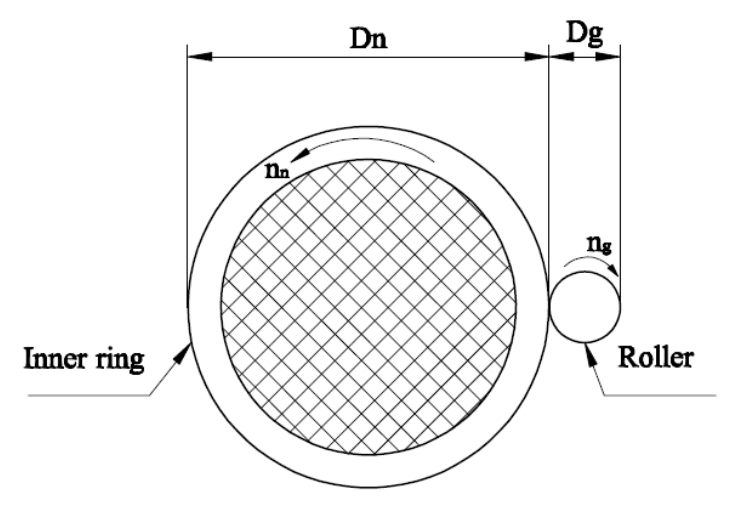

Figure 4. Testing bearing configuration.

According to [17], the slip rate can be obtained from Equation (1),

$$
s=1-\frac{D_{g} n_{g}}{D_{n} n_{n}}
$$

where $n_{g}$ is the roller speed measured by the displacement sensor; $n_{n}$ is the inner ring speed; $D_{g}$ is the roller diameter; and $D_{n}$ is the outside diameter of the inner ring. 


\subsubsection{Lubrication and Cooling Device}

The cooling device consists of two chillers, which are connected to the motorized spindles through the inlet and outlet pipes. Before the formal test beginning, we open the chillers to cool the motorized spindle. The lubrication device is composed of a peristaltic pump, and the touch screen is used to adjust the lubricating oil quantity in order to drip-lubricate the test bearing.

\subsubsection{Loading Device}

A radial load is applied to the contact pair of the roller-inner ring by manual loading, which meets the requirements of a light load. The front end of the loading lever is connected with the pressure sensor with a digital display function. In order to ensure uniform loading, one end of the spherical loading head is connected with the pressure sensor, and the other end is connected with the loading board at the front of the roller motorized spindle.

\subsubsection{Test System}

The test system mainly includes a speed measurement subsystem of the roller and the inner ring, radial load measurement subsystem, and vibration measurement and temperature measurement subsystem. The rotational speed is measured by the displacement sensor (ZA series eddy current displacement sensor), the radial load is measured by the pressure sensor (JLBM-100kg tension pressure sensor), the vibration is measured by an acceleration sensor (INV9822 acceleration sensor), and the temperature is tested by an infrared thermal imager (FLIR E5 infrared thermal imager, and the emissivity value is 0.95). All the data can be stored in the computer through the upper computer software. The signals are obtained by the sensor module, and the acquired data is transmitted to the computer terminal through the NI-6002 data acquisition card; then, the data are analyzed and processed in the developed software [20].

\subsection{Work Principle of the Test Rig}

The main test sample is the friction pair of the roller and inner ring. The components of the test rig are shown in Figure 5. In order to ensure the safety of the experiment, a protective cover with an observation window was designed and machined. Furthermore, the support of the test foundation platform is composed of a linear guide rail and a dovetail platform, which can precisely adjust the roller in the $\mathrm{x}$ and $\mathrm{y}$ directions. In addition, it is convenient to dismantle and install the new bearing after the experiment. The roller and the inner ring are controlled by the two motorized spindles, respectively.

As for the alignment of the test rig and attainment of a better linear contact between the roller and inner ring, the following procedures were taken before the experiment: The first step is to install the test rig and measure the levelness of the supporting platform through the gradienter. The second step is to align the test rig. After each part is assembled, the dial indicator is fixed on motorized spindle 1 , and the tip of the dial is aligned with the inner ring. Then, the dovetail platform moves along the $x$ direction and the dial indicator hardly turns, so the roller and inner ring have better parallelism and alignment. The third step is to observe the load fluctuation. After the load is applied, we rotate the inner ring slowly to drive the roller to rotate. In the test system, the fluctuation of the load during the rotation is observed, and the pressure sensor shows a fluctuation error of about $5 \%$, which indicates that the contact load fluctuation is small. If the fluctuations are large, we adjust the position of the motorized spindle of the roller to reduce the fluctuation.

Before operating the test system to see if it works, we turned on the water chiller to cool the motorized spindle; meanwhile, we also turned on the lubrication system and loading system. According to the inner ring speed, we regulated the frequency of the frequency converter to control spindle 2. Once the test rig starts, the roller rotates, following up the inner ring, and the data acquisition system adopts the upper computer to process the data, which are collected by the displacement sensor and pressure sensor. Moreover, the data are converted into speed and load information and stored 
in the computer. The temperature in the key contact area is recorded by the infrared thermal imager, and the data can be stored in the computer. Thus, based on the data information such as speed, load, temperature, and slip rate, the skidding damage mechanism of the rolling bearing can be obtained from the perspective of multi-information integration.

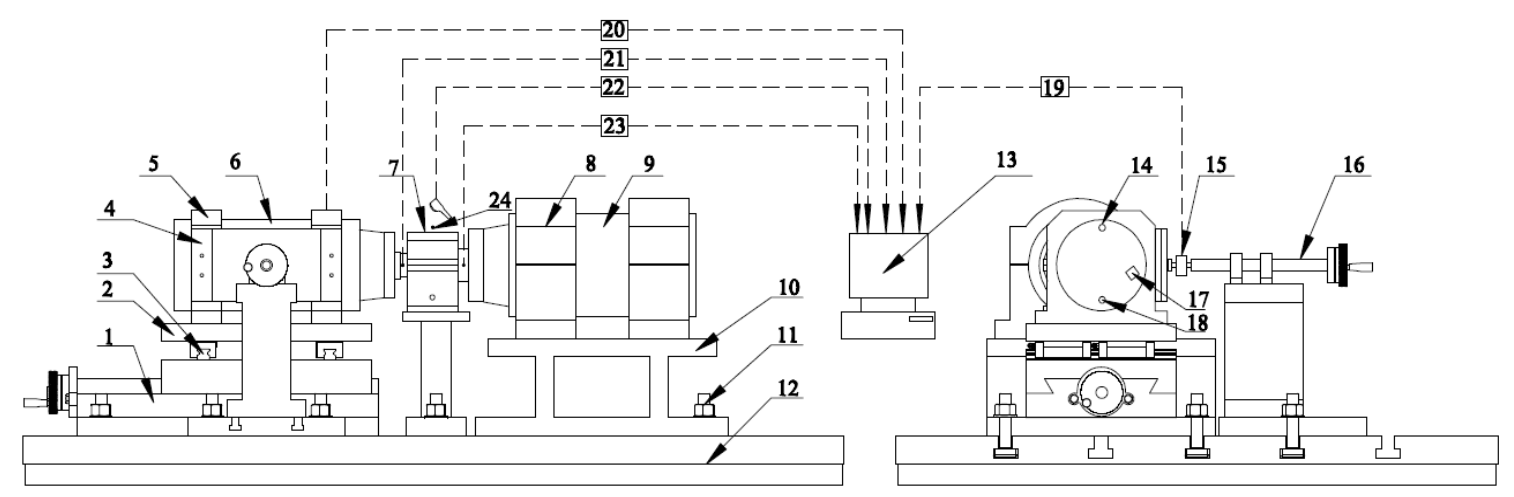

Figure 5. Components of the test rig: (1) Dovetail platform; (2) Support platform; (3) Linear guides; (4) Loading board; (5) Spindle fixture; (6) Motorized spindle 1; (7) Protective cover; (8) Spindle fixture; (9) Motorized spindle 2; (10) Spindle support frame; (11) Bolt; (12) Vibration reduction table; (13) Computer; (14) Water outlet; (15) Pressure sensor; (16) Loading screw; (17) Power connector; (18) Water inlet; (19) Pressure testing system; (20) Vibration testing system; (21) Revolving speed testing system (displacement sensor); (22) Infrared thermograph temperature measuring system; (23) Revolving speed testing system (displacement sensor); (24) Lubricating device.

In order to measure the real slip of the cylindrical roller bearing, the skid damage test rig simulates the dynamic contact between the bearing ring and roller by starting the inner ring motorized spindle to run the roller, and the inner ring speed, radial load, the amount of lubricating oil can be adjusted. To sum up, the mechanism of skidding damage of the roller bearing under different working conditions is fully studied.

\section{Results and Discussion}

\subsection{Experiment Design}

The difference between this experiment and previous studies is that the method of the contact pair of the roller and the inner ring is improved into horizontal contact, and the test method is improved into running the roller by driving the inner ring motorized spindle. Based on the control variable method, the time-varying slip and temperature distribution under different radial loads, inner speeds, and lubricating oil conditions are studied. Each condition of the tests is run five times.

\subsection{Results and Analysis}

The experimental treatment method in this manuscript is as follows. The temperature value is the surface temperature of the roller in the contact area when the roller stops, and the slip rate is the value at which the roller speed reaches its maximum value at the stable stage of the test.

\subsubsection{Effect of the Radial Load on the Slip Rate and Temperature}

The test conditions are as follows: the inner ring speed is $1050 \mathrm{r} / \mathrm{min}$; the lubricating oil quantity is $5 \mathrm{~mL} / \mathrm{min}$; the radial loads are $70 \mathrm{~N}, 100 \mathrm{~N}, 130 \mathrm{~N} 160 \mathrm{~N}$, and $190 \mathrm{~N}$. The error between the measured value and the benchmark value is shown in Table 1 . 
Table 1. The error of radial load.

\begin{tabular}{ccc}
\hline Benchmark & Measured Value & Error \\
\hline $70 \mathrm{~N}$ & $64 \mathrm{~N}$ & $8 \%$ \\
$100 \mathrm{~N}$ & $95 \mathrm{~N}$ & $5 \%$ \\
$130 \mathrm{~N}$ & $127 \mathrm{~N}$ & $2 \%$ \\
$160 \mathrm{~N}$ & $151 \mathrm{~N}$ & $5 \%$ \\
$190 \mathrm{~N}$ & $181 \mathrm{~N}$ & $4 \%$ \\
\hline
\end{tabular}

Figure $6 a$ analyzes the variation tendency of the temperature and slip in the contact area under different radial loads. The results show that the temperature in the contact area continues to increase with the increase of the radial load, but the trend gradually slows down. The reason is that the slip rate decreases rapidly due to the radial load increase, which reduces the temperature in the contact area to some extent. Figure $6 b$ is the scatter diagram of load for the five cases.
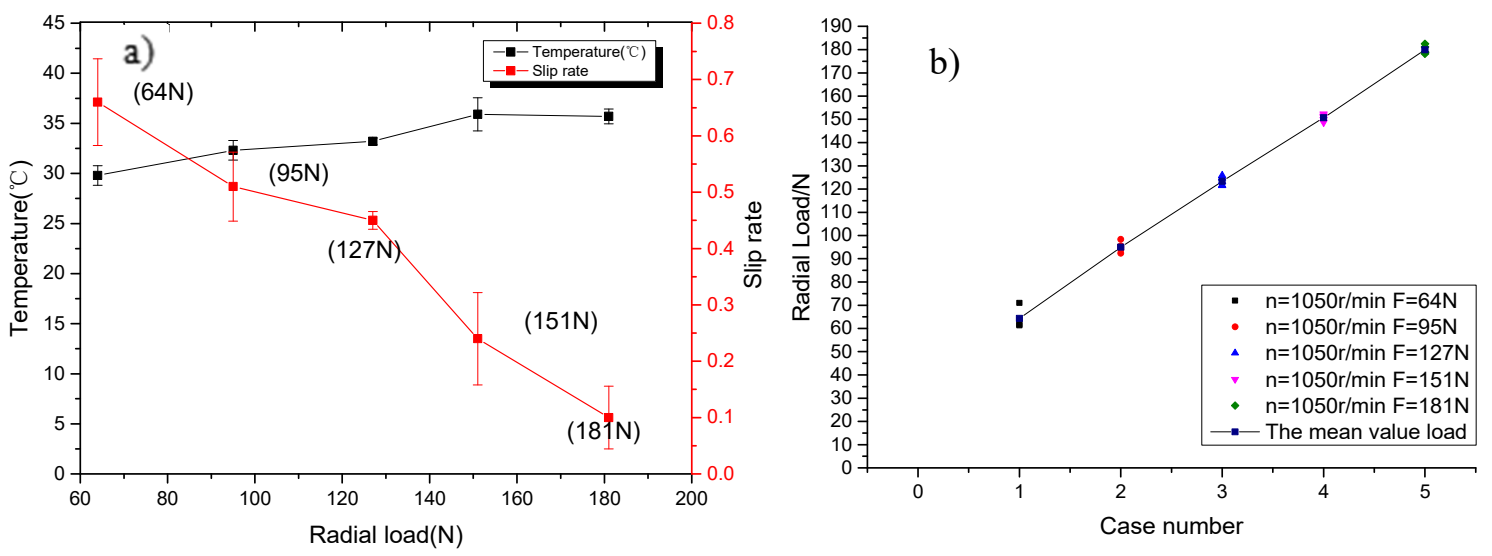

Figure 6. (a) Temperature and slip rate of the contact area under different radial loads. (b) Scatter diagram of load.

\subsubsection{Effect of the Inner Ring Speed on the Slip Rate and Temperature}

The test conditions are as follows: the radial load is $130 \mathrm{~N}$; the lubricating oil quantity is $5 \mathrm{~mL} / \mathrm{min}$; the inner ring speeds are $1050 \mathrm{r} / \mathrm{min}, 1230 \mathrm{r} / \mathrm{min}, 1410 \mathrm{r} / \mathrm{min}, 1590 \mathrm{r} / \mathrm{min}$, and $1770 \mathrm{r} / \mathrm{min}$. The measured minimum load is $125 \mathrm{~N}$, the benchmark is $130 \mathrm{~N}$, and the error of them is $3 \%$. Figure 7 a shows that the temperature in the contact area increases continuously with the increase of the inner ring speed. From the general trend, the slip increases with the increase of the inner ring speed. The rotary accuracy of the clamping mechanism is higher in the improved test rig. The load has inevitably small fluctuations that result from the roller clamping end having run-out within $0.02 \mathrm{~mm}$. Due to the extremely light load (radial load is less than $200 \mathrm{~N}$ ), this small load fluctuation also has a significant effect on the temperature rise and slip rate in the contact area. For example, when the speed is $1590 \mathrm{r} / \mathrm{min}$ and the load is $125 \mathrm{~N}$, the slip rate is 0.54 . When the speed is $1770 \mathrm{r} / \mathrm{min}$ and the load is $126 \mathrm{~N}$, the slip rate is 0.53 . As the load in the working conditions fluctuates slightly, the load under the condition of a rotating speed of $1770 \mathrm{r} / \mathrm{min}$ is larger than that under the condition of $1590 \mathrm{r} / \mathrm{min}$, and so the slip has a slight decreasing tendency. The overall trend showed that the higher the rotational speed, the higher the slip rate and temperature. Figure $7 \mathrm{~b}$ is the scatter diagram of load for the five cases. 

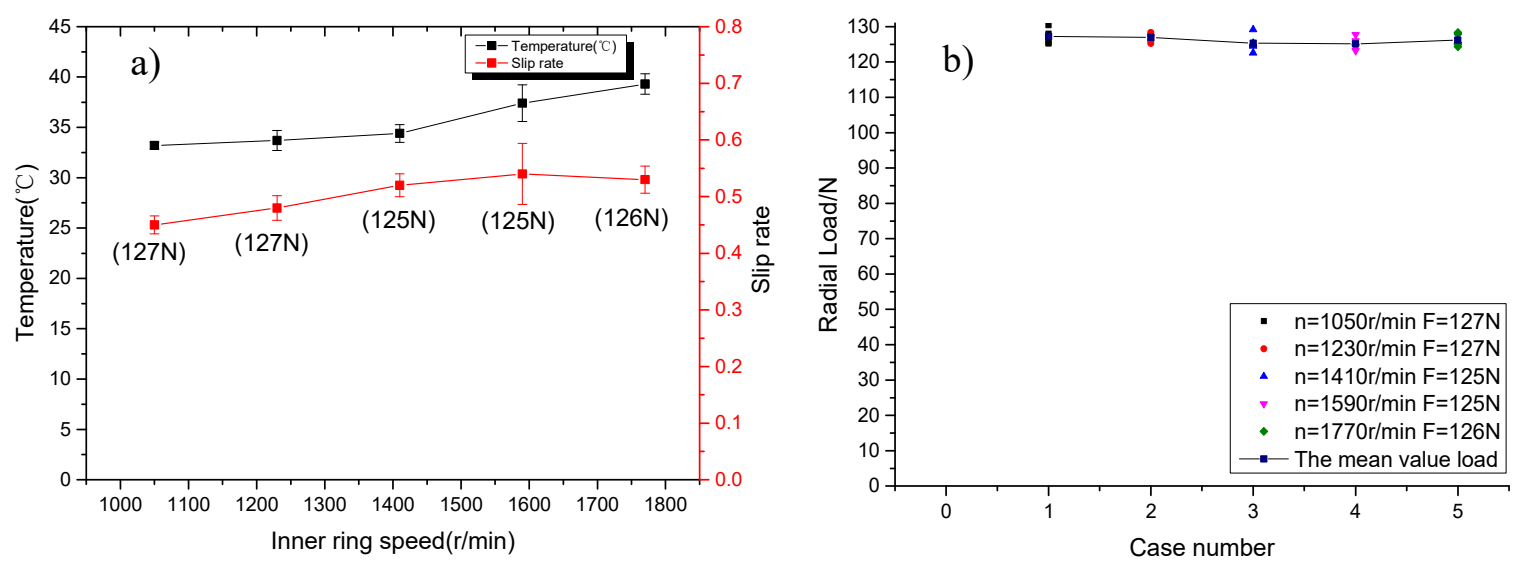

Figure 7. (a) Temperature and slip rate of the contact area under different inner ring speeds. (b) Scatter diagram of load.

\subsubsection{Effect of the Lubricating Oil Quantity on the Slip Rate and Temperature}

The test conditions are as follows: the inner ring speed is $1050 \mathrm{r} / \mathrm{min}$; the radial load is $130 \mathrm{~N}$; and the lubricating oil quantities are $3 \mathrm{~mL} / \mathrm{min}, 4 \mathrm{~mL} / \mathrm{min}, 5 \mathrm{~mL} / \mathrm{min}, 6 \mathrm{~mL} / \mathrm{min}$, and $7 \mathrm{~mL} / \mathrm{min}$. The measured minimum load is $124 \mathrm{~N}$, the benchmark is $130 \mathrm{~N}$, and the error of them is $4 \%$. Figure 8 a shows that the temperature in the contact area continues to decrease with the increase of the lubricating oil. With the increase of lubricating oil quantity, the trend of slip has no obvious linear relationship. When the lubricating oil quantity is $4 \mathrm{~mL} / \mathrm{min}$, the slip rate drops. According to the load analysis, the load value under this condition is $127 \mathrm{~N}$ because of the inevitable fluctuation of the load. Meanwhile, the load is larger than the load value under other conditions, so the slip rate under this condition is the minimum. As can be seen from the variation trend in Figure 8a, with the increase of lubricating oil, the temperature decreases gradually, but there is no direct relationship between the lubricating oil quantity and slip rate. It can be concluded that the coupling effect between different loads and lubricating oil quantities has a certain influence on the slip rate. Figure $8 b$ is the scatter diagram of load for the five cases.
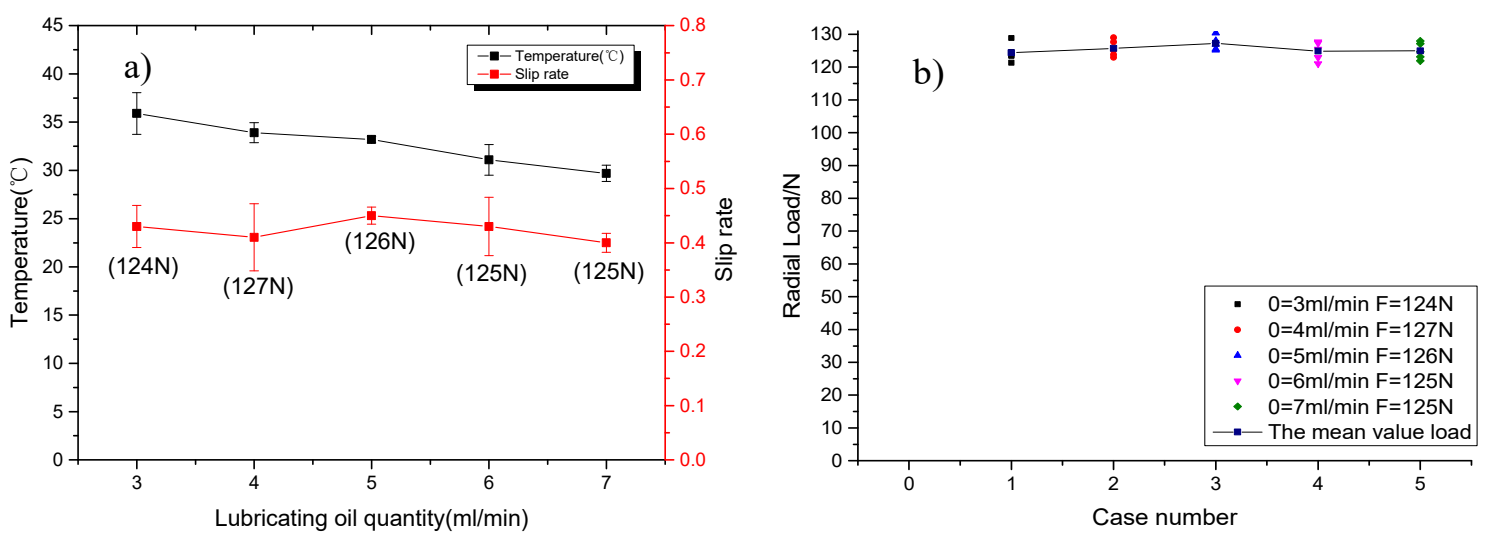

Figure 8. (a) Temperature and slip rate of the contact area under different lubricating oil quantities.

(b) Scatter diagram of load.

\subsubsection{Effect of the Lubricating Oil Cleanliness on the Slip Rate and Temperature}

The test conditions were as follows: the inner ring speed is $2100 \mathrm{r} / \mathrm{min}$; the radial load is $120 \mathrm{~N}$; and the lubricating oil quantity is $10 \mathrm{~mL} / \mathrm{min}$. The contaminated oil is the lubricating oil with mechanical impurity, and the rest is clean oil. Figure 9 shows the dynamic lubrication failure process of the contact pair in rolling bearings with the time-varying slip and temperature distribution. It can be seen from Figure $9 \mathrm{a}, \mathrm{c}$ that the temperature under the condition of clean oil is $34.8^{\circ} \mathrm{C}$, and the temperature under the condition of contaminated oil is $35.8^{\circ} \mathrm{C}$. The temperature rises sharply in the starting stage of 
the test, and then reaches the stable stage when the roller speed tended to be stable. During the stopping stage, the temperature decreases rapidly at first, and then rises again before the test stops completely. It can be seen from Figure $9 b$,d that the variation trend of the slip rate is consistent with that of temperature. The slip rate under clean oil is 0.684 , and that of contaminated oil is 0.722 . In the starting state of the test, the slip rate is large and then decreases until the roller speed tends to be stable and remains stationary. During the stopping stage, the slip rate decreases rapidly at first, and then rises rapidly before it stops completely. The possible reason is that the speed of the inner ring reduces rapidly in the initial stage of shutdown, and then the speed of the roller reduces roughly to the same degree. The speed of the roller reduced rapidly in a short time before the test stopped completely, resulting in the large slip rate.

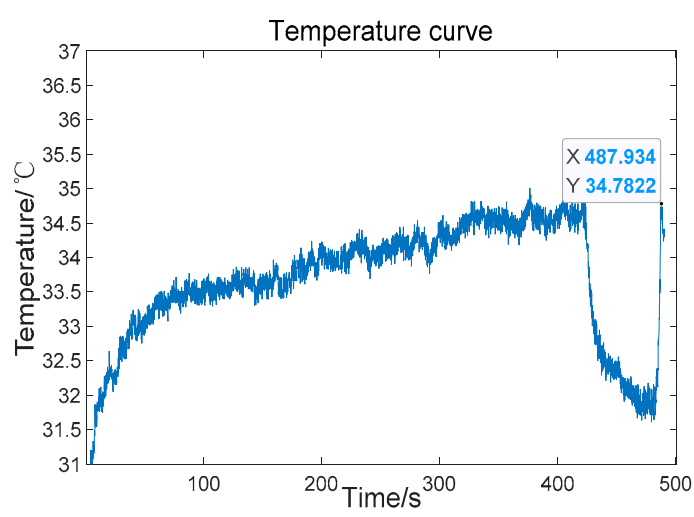

(a)

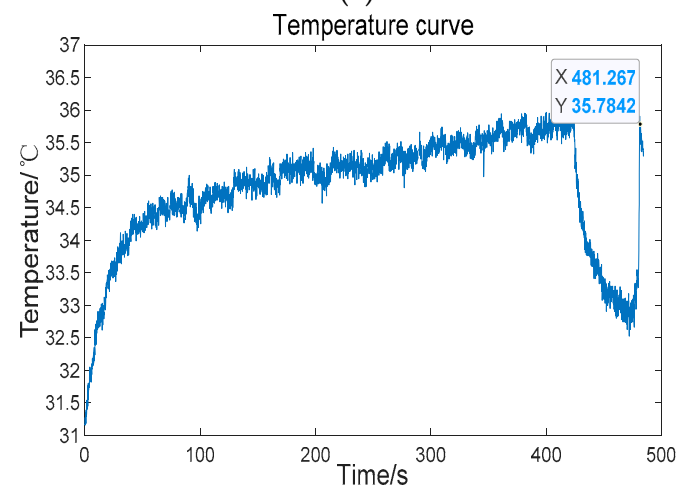

(c)

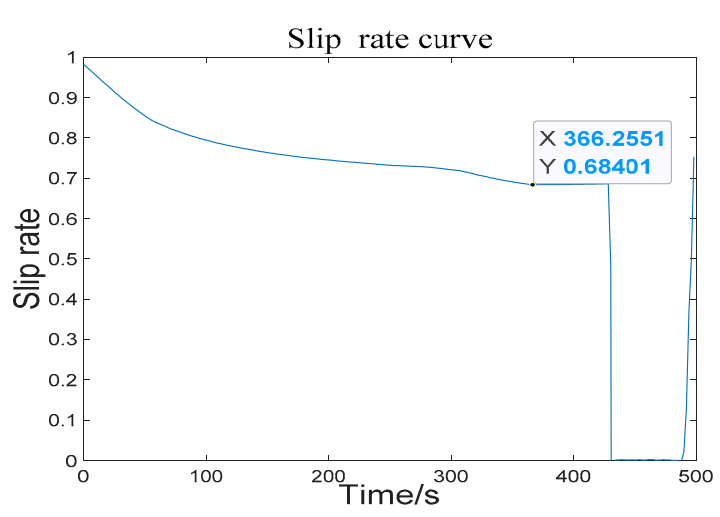

(b)

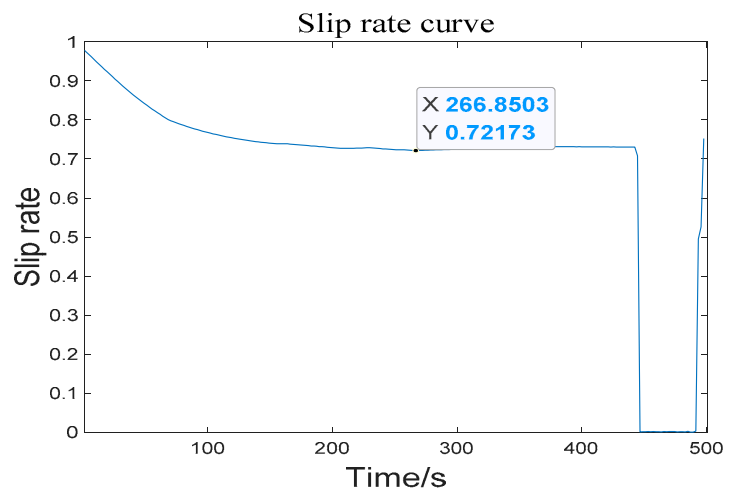

(d)

Figure 9. Temperature and slip rate of the contact area under different lubricating oil cleanliness. (a) Temperature curve (clean oil); (b) Slip rate curve (clean oil); (c) Temperature curve (contaminated oil); (d) Slip rate curve (contaminated oil).

\subsubsection{Analysis of the Surface Morphology and the Mechanism of Skidding Damage}

Figure 10a,b shows the surface morphology of the roller and inner ring before the test, and Figure 10c,d shows the surface morphology of the roller and inner ring after skid damage. LEXT OLS4000 is used to obtain the surface topography and roughness data. The test conditions are as follows: the inner ring speed is $2250 \mathrm{r} / \mathrm{min}$; the radial load is $120 \mathrm{~N}$; and the lubricating oil quantity is $10 \mathrm{~mL} / \mathrm{min}$. The test results show that the slip rate is 0.9306 at the initial time of the skidding damage.

According to the comparison of the surface morphology of the inner ring before and after the test, the surface of the inner ring has obvious adhesion wear, and the damaged area has cracks and scratches. The reason for this phenomenon may be a large slip between the roller and the inner ring. When the oil film breaks, the direct contact between the roller and the inner ring causes the material to transfer to each other. The surface roughness of the inner ring is $0.378 \mu \mathrm{m}$ before the test, and increases to $0.54 \mu \mathrm{m}$ after the test. 


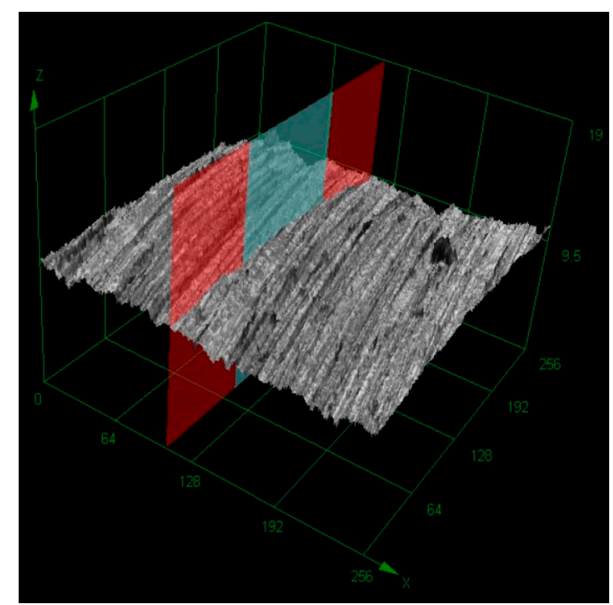

(a)

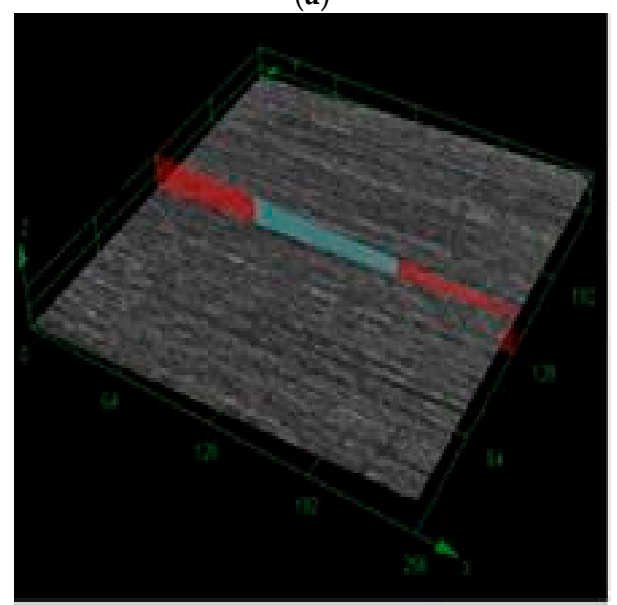

(b)

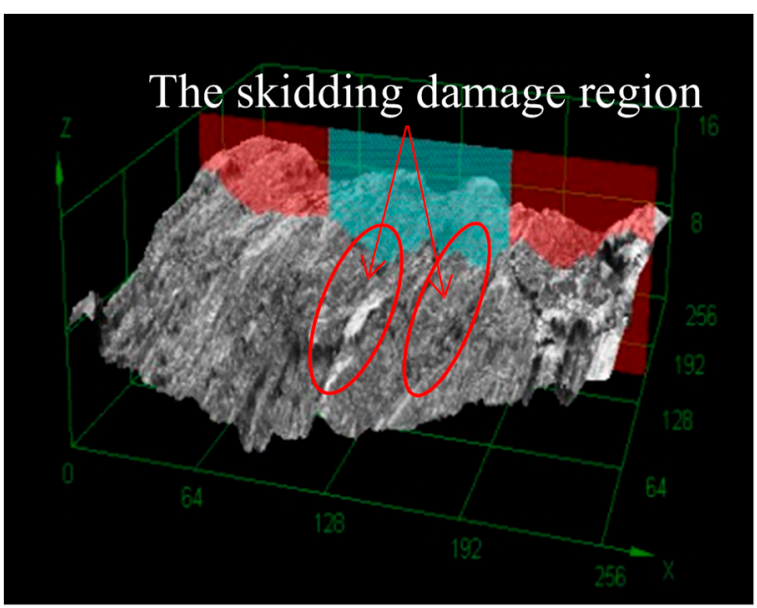

(c)

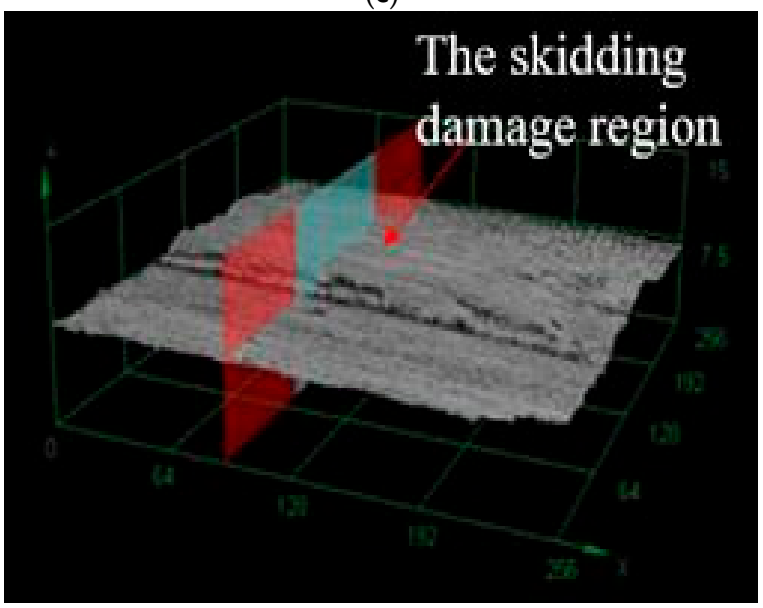

(d)

Figure 10. Surface morphology of the roller and inner ring. (a) Roller morphology before the test; (b) Inner ring morphology before the test [20]; (c) Roller morphology after the test; (d) Inner ring morphology after the test [20].

According to the comparison of the surface morphology of the roller before and after the test, it can be seen that there are burning points with different sizes and cracks on the edge of the damaged area. In addition, the temperature increased significantly at the beginning of the test, indicating that the skid damage caused a high temperature instantaneously, and the high temperature caused a burning pit on the surface of the material. Thus, skid damage may tend to be thermal failure. The surface roughness of the roller was $0.446 \mu \mathrm{m}$ before the test, and increased to $0.692 \mu \mathrm{m}$ after the test.

Figure 11a,b shows the surface morphology of the roller and inner ring before the test, and Figure 11c,d shows the surface morphology of the roller and inner ring after skid damage. The test conditions are as follows: the inner ring speed is $4350 \mathrm{r} / \mathrm{min}$; the radial load is $100 \mathrm{~N}$; and the lubricating oil quantity is $1 \mathrm{~mL} / \mathrm{min}$. The test results show that the slip rate is 0.9878 at the initial time of skidding damage.

It can be seen from Figure 11c that there are peeling pits on the roller surface after skidding damage, which indicates that skidding damage can lead to material migration. As can be seen from Figure $11 d$, the surface of the inner ring has the material adhesive, and some areas of the surface are covered with black burning points. Therefore, there may be a thermal failure phenomenon in the skidding damage of roller bearings. 


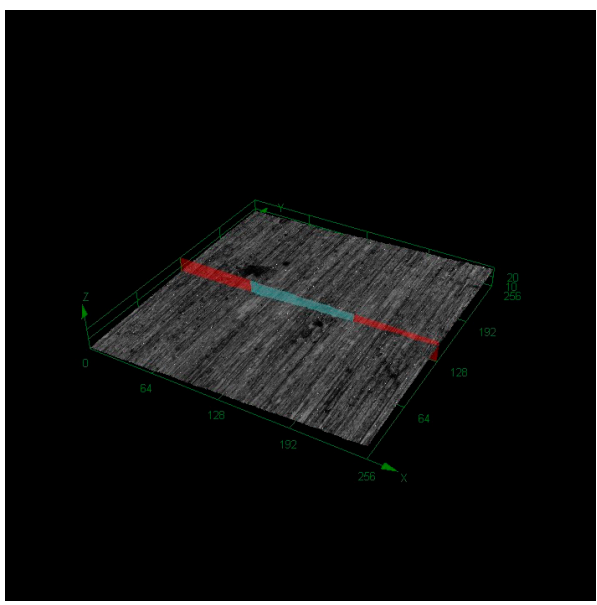

(a)

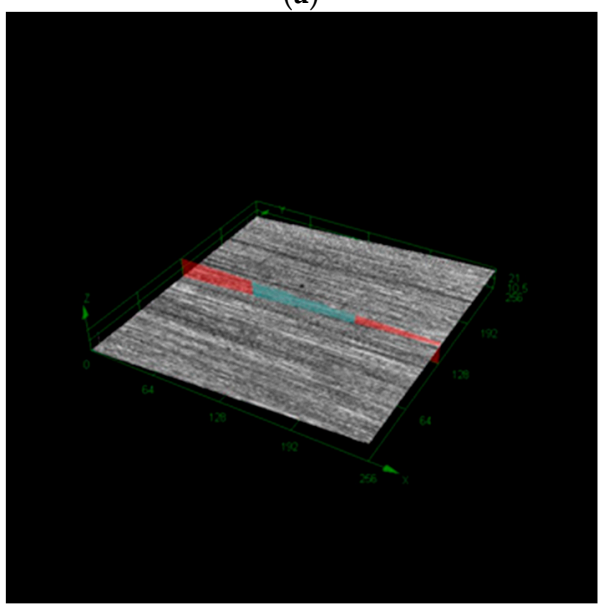

(b)

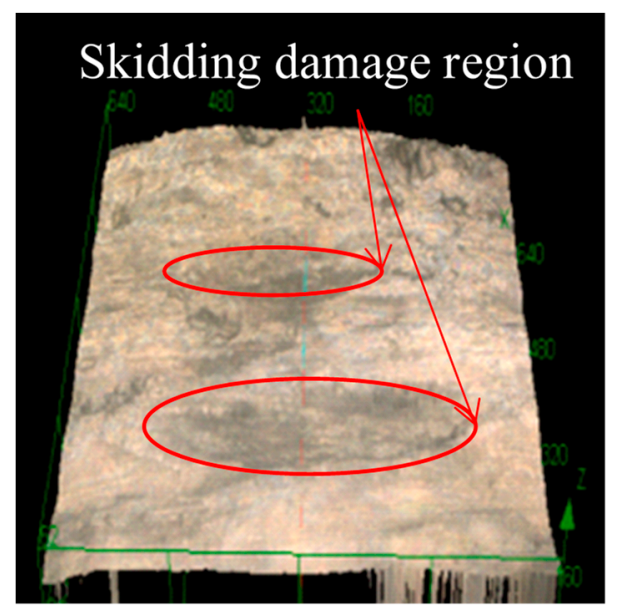

(c)

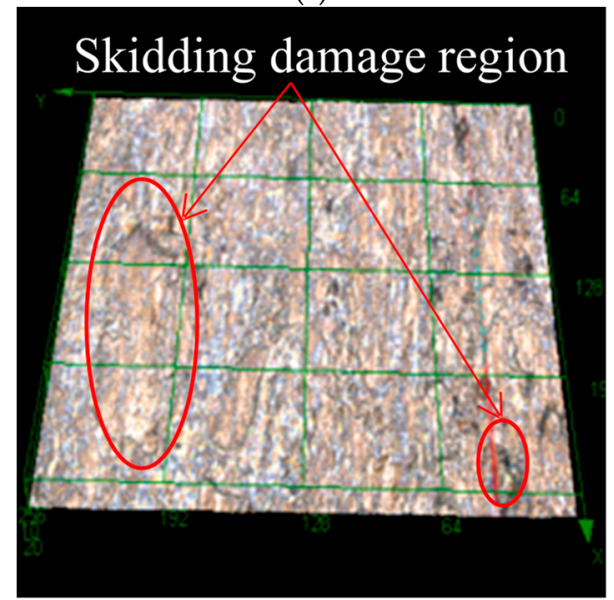

(d)

Figure 11. Surface morphology of the roller and inner ring. (a) Roller morphology before the test; (b) Inner ring morphology before the test; (c) Roller morphology after the test; (d) Inner ring morphology after the test.

The surface roughness of the inner ring was $0.123 \mu \mathrm{m}$ before the test, which increased to $0.629 \mu \mathrm{m}$ after the test. The surface roughness of the roller was $1.127 \mu \mathrm{m}$ before the test, which increased to $1.763 \mu \mathrm{m}$ after the test. It also can be inferred that the larger slip rate can lead to more obvious surface roughness changes before and after the test.

The slip rate has a significant effect on the skidding damage of a rolling bearing. By comparing the skidding damage cases, it can be inferred that the greater the slip rate, the more serious the surface damage. The test results show that the skidding damage always occurs under larger slip rates, especially when the slip rate is bigger than 0.9. Combining with the surface morphology and the time-varying slip and temperature curve, it can be concluded that the skid damage under extremely light load is the comprehensive effect of adhesive wear and thermal failure.

\section{Conclusions}

In this study, a new horizontal skid damage test rig was developed. The running mode of the inner ring driving the roller was adopted to simulate the rolling/sliding contact between the roller and inner ring under the real slip. A test system was developed to measure the speed of the roller and the inner ring in real time so as to obtain the time-varying trend of slips under given conditions.

The influence of radial load, inner ring speed, and lubricating oil quantity on the skidding damage of rolling bearings were studied. The results show that the radial load has the most significant effect on the time-varying slip rate in the contact area, and the slip rate decreases as the load increases. The effect 
of lubricating oil quantity on skidding damage is not significant. Furthermore, the influence of the lubricating oil cleanliness on the skidding damage of rolling bearings was obtained. Combined with the time-varying temperature and slip curve, it is concluded that the temperature rises and slip rate of the bearing are smaller under the clean oil conditions. In addition, the dynamic lubrication failure process of the contact pair in rolling bearings with the time-varying slip and temperature distribution was revealed.

The surface roughness data demonstrated that the skidding damage has a certain effect. As for the cases of skid damage, the surface roughness of the contact area generally increased after the experiment. It also can be inferred that the larger slip rate can lead to more obvious surface roughness changes before and after the test. In various skidding damage cases, it can be inferred that the skidding damage always occurs when the slip ratio is bigger than 0.9. The results show that the skid damage under extremely light load is the comprehensive effect of adhesive wear and thermal failure. This study can provide an effective reference for improving the reliability and service life of aviation bearing.

Author Contributions: Conceptualization, J.L.; Data curation, W.C. and J.X.; Formal analysis, K.H. and Q.W.; Funding acquisition, J.L.; Investigation, J.X.; Methodology, J.X. and J.L.; Software, Q.W. and K.H.; Writing-original draft, J.X. and J.L.; Writing-Review and editing, J.L. All authors have read and agreed to the published version of the manuscript.

Funding: This research was funded by The Program of State Key Laboratory of Mechanical Transmissions (No. SKLMT-KFKT-201808), The National Natural Science Foundation of China (No. 51505361), and The Innovative Talents Promotion Plan in Shaanxi Province (No. 2017KJXX-58).

Acknowledgments: The authors would like to thank Wei Chen for their valuable discussions on this article.

Conflicts of Interest: The authors declare no conflict of interest.

\section{References}

1. Tassone, B. Roller bearing slip and skidding damage. J. AIRCR 1975, 12, 281-287. [CrossRef]

2. Asano, K. Recent development in numerical analysis of rolling bearings basic technology series of bearings. KOYO Eng. J. 2002, 160, 65-70.

3. Jones, A. A general theory for elastically constrained ball and radial roller bearings under arbitrary load and speed conditions. J. Fluid Eng. 1960, 82, 309-320. [CrossRef]

4. Harris, T. An analytical method to predict skidding in high speed roller bearings. ASLE. Trans. 1966, 9, $229-241$. [CrossRef]

5. Poplawski, J. Slip and cage forces in a high-speed roller bearing. J. Lubr. Technol. 1972, 94, 143-150. [CrossRef]

6. Rumbarger, J.; Filetti, E.; Gubernick, D. Gas turbine engine mainshaft roller bearing-system analysis. J. Lubr. Technol. 1973, 95, 401-416. [CrossRef]

7. Walters, C. The dynamics of ball bearings. J. Lubr. Technol. 1971, 93, 1-10. [CrossRef]

8. Gupta, P. On the geometrical imperfections in cylindrical roller bearings. J. Tribol. 1988, 110, 13-18. [CrossRef]

9. Gupta, P. On the dynamics of a tapered roller bearing. J. Tribol. 1989, 111, 278-287. [CrossRef]

10. Wang, Y.-L.; Wang, W.-Z.; Zhang, S.-G.; Zhao, Z.-Q. Investigation of skidding in angular contact ball bearings under high speed. Tribol. Int. 2015, 92, 404-417. [CrossRef]

11. Takabi, J.; Khonsari, M. On the dynamic performance of roller bearings operating under low rotational speeds with consideration of surface roughness. Tribol. Int. 2015, 86, 62-71. [CrossRef]

12. Han, Q.; Li, X.; Chu, F. Skidding behavior of cylindrical roller bearings under time-variable load conditions. Int. J. Mech. Sci. 2018, 135, 203-214. [CrossRef]

13. Tu, W.; Shao, Y.; Mechefske, C. An analytical model to investigate skidding in rolling element bearings during acceleration. J. Mech. Sci. Technol. 2012, 26, 2451-2458. [CrossRef]

14. Niu, L.; Cao, H.; He, Z.; Li, Y. An investigation on the occurrence of stable cage whirl motions in ball bearings based on dynamic simulations. Tribol. Int. 2016, 103, 12-24. [CrossRef]

15. Cao, W.; Wang, J.; Pu, W.; Zhang, Y.; Wu, J.; Chu, K.; Wu, H. A study on the effect of acceleration on slip velocity and lubrication performance in cylindrical roller bearings. Proc. Inst. Mech. Eng. Part J J. Eng. Tribol. 2016, 230, 1231-1243. [CrossRef] 
16. Selvaraj, A.; Marappan, R. Experimental analysis of factors influencing the cage slip in cylindrical roller bearing. Int. J. Adv. Manuf. Tech. 2011, 53, 635-644. [CrossRef]

17. Li, J.; Chen, W.; Xie, Y. Experimental study on skid damage of cylindrical roller bearing considering thermal effect. Proc. Inst. Mech. Eng. Part J J. Eng. Tribol. 2015, 228, 1036-1046. [CrossRef]

18. Zhang, W.; Chen, W.; Liu, Z. Experimental study on thermal effect of tilted roller pairs in rolling/sliding contacts. Ind. Lubr. Tribol. 2017, 69, 225-233. [CrossRef]

19. Peng, Y.; Cai, J.; Wu, T.; Cao, G.; Kwok, N.; Zhou, S.; Peng, Z. Online wear characterisation of rolling element bearing using wear particle morphological features. Wear 2019, 430, 369-375. [CrossRef]

20. Li, J.; Chen, W.; Xue, J.; Han, K.; Wang, Q. Effect of Multiple Factors on Identification and Diagnosis of Skidding Damage in Rolling Bearings under Time-Varying Slip Conditions. Appl. Sci. 2019, 9, 3033. [CrossRef]

(C) 2019 by the authors. Licensee MDPI, Basel, Switzerland. This article is an open access article distributed under the terms and conditions of the Creative Commons Attribution (CC BY) license (http://creativecommons.org/licenses/by/4.0/). 